\title{
Research on Digitalization of the Museum Industry in China- Based on SWOT-PEST Model
}

\author{
Jingyi Peng ${ }^{1}$ \\ ${ }^{1}$ General Institute, Art management, Gachon University, Seongnam, Korea \\ Correspondence: Jingyi Peng, General Institute, Art management, Gachon University, Seongnam, Korea. E-mail: \\ 429522914@qq.com
}

Received: December 27, 2021

Accepted: January 12, 2022

Online Published: January 25, 2022

doi:10.20849/ajsss.v7i1.982

URL: https://doi.org/10.20849/ajsss.v7i1.982

\begin{abstract}
As the main institution for the collection, the museum plays the role of collecting, publicity, education, and scientific research. It scientifically researches the collection, holds exhibitions, disseminates historical and scientific knowledge, providing the public with culture, education and appreciation services. The museum is a concentrated space of culture, contains human memory, and is a representative of the heritage and customs in a city, and even the country. With the development of technologies such as networks, the Internet of Things, digital and mobile communication, the application of high-tech in museums has continued to expand and deepen. Museums containing ancient civilizations are rejuvenated with the blood of new technology, presenting the long history to the public with a brand-new look, which become an unstoppable mainstream trend in the future. From the early "digital museums" to "smart museums" today, which has benefited from the development of science and technology. The integration of emerging technologies into museums, and the promoting the treasures of human civilization are by no means as simple as using technology to support them, which should start from a comprehensive and overall consideration. Therefore, this article starts from digitalization of the museum industry, uses the SWOT-PEST model as the analysis framework, and deeply explores the various factors in the development of museums in China, and discuss the strategic advice.
\end{abstract}

Keywords: digitalization, museum, SWOT-PEST Model

\section{Introduction}

Since the 1980s, the Museum has been moving towards the digitalization process in China. Especially after 2000, it has accelerated the pace of development, from the basic infrastructures to management systems, digital exhibitions, mobile applications, and so on, all kinds of Digital projects developed in an all-round way, and the digitization of the museum industry is shown flourish. With the further development of the "Internet of Things", "cloud computing" and "big data", museums gradually use these technologies to further develop into more advanced "smart" museums, which is another optimization for digitalization of the museum industry.

\section{Overview of Digitalization of the Museum Industry in China}

\subsection{Background of Digitalization of the Museum Industry in China}

The concept that the traditional museum industry combined with digitization originated in the United States in the early 1990s. In 1998, the then-Vice President of the United States Al Gore first proposed the concept of "digital earth", which is based on computer technology, multimedia technology and large-scale storage technology, and broadband network is used as a link to spread the Three-dimensional data on the earth, and use it as a tool to support and improve human activities and life quality (Tong, 1998). As digitization penetrates daily life, museums are also integrated with the concept. At almost the same period in China, the museum industry entered into digital exploration, and digital technology was applied to more work, including display, collection protection, management, research, and educational functions, which is the mark the beginning of the digitalised museum industry.

\subsection{The Definition and Meaning of Digitalization in the Museum Industry}

Since the 1990s, the Museum industry has entered the new industrial stage for digitalised exploration in China. After more than 30 years the development, the museum gradually produced "digital museums", and more advanced status "smart museum". 


\subsubsection{The Digital Museum}

Since 1990, the Library of Congress launched the "Memory of America" project, which aims to digitally collect and store many manuscripts, books, printed texts, and video recordings of American history and culture in the Library of Congress, and establish a database, which can spread to individuals, families, and civil organizations so on, through the Internet (Zhang, 2016). Meanwhile, the launch of the American Memory Project marked the beginning of the digital age in the museum, which is a big step in providing free, fast and convenient information services to the public. The American scholar Nicholas Negroponte first proposed the concept of digitalization in his book "Being Digital". What is thought-provoking in the book is that computing is no longer only related to computers, it determines our Survive (Zhao, 1997). Under the influence of these, the concept of the digital museum began to take shape. Digital technology intervenes in the gathering information of collection in the museum, converts different information such as pictures, sounds, texts, videos, etc. into measurable digital information, and then switch these data into display sources that are suitable for the audience's understanding and comfortable experience, such as putting digital text introduction, displaying the electronic picture, and showing video files. In particular, the digital museums characterized by digitization, networking, and virtualization has transformed collections into different mediums, greatly enhancing the performance capabilities of museum displays. Digital technology has been developed in museums for more than half a century. During this period, new technologies continue to emerge. For example, new media technologies, sensor technologies, and big data technologies have entered daily life. All kinds of new inventions provide strong technical support for the transformation of digitalization, and the smart museum phase is gradually taking shape.

\subsubsection{The Smart Museum}

In 2008, at the U.S. Business Leaders Conference, IBM CEO Samuel Palmisano first proposed the concept of a "smarter planet": with the help of low-cost sensor technology and network services, sensors can be embedded and equipped into the power grid, Railroads, buildings, dams, oil and gas pipelines and other objects form a "things-to-things connection", and then integrate them through supercomputers and cloud computing to achieve a high degree of integration between human society and the physical world (Chen, 2013).

As the concept of smart is generally accepted, recognized and widely disseminated by the public, people try to use the Internet and cloud computing technology to more accurately apply the concepts to all walks of life, and the concept of "smart museum" was born. At present, it is generally defined as: through the full use of the Internet of Things, cloud computing, big data, artificial intelligence and other new-generation information technologies to perceive, calculate, and analyze information related to the operation in the museum, so as to realize the smarter collect, protection, display, dissemination, research and management activities. The new model and form development significantly enhance the service, protection, and management capabilities in the museum.

\section{Analysis of Digitalised Museum in China Based on SWOT-PEST Model}

\subsection{SWOT-PEST Model}

The SWOT analysis method is also called the situation analysis method, which is an analysis method commonly used by enterprises when making strategic planning. This analysis method was proposed by Harvard Professor Andrews in 1971. The SWOT analysis method lists the internal S (strengths), W (weakness), O (opportunities), and $\mathrm{T}$ (threats) of the research objects obtained from the investigation into a matrix, and analyzes the various factors that match each other. The model can systematically analyze the status of the research object, and formulate corresponding development strategies based on the analysis results (Chen, 2016).

The PEST analysis method is the basic tool for analyzing the external environment of industrial development, through political, economic, technology and social, which four aspects grasp the macro environment in the industrial development ( $\mathrm{Li}, 2016)$.

The so-called SWOT-PEST analysis method is to systematically integrate the internal micro-environment and external macro-environment of the research object to the SWOT-PEST analysis matrix, as shown in the table1. Systematically analyze the advantages and disadvantages of the research object in terms of politics, economy, society, and technology, as well as identify the opportunities, risks, and key influencing factors, and formulate strategic development plans. Therefore, this article uses the SWOT-PEST analysis method to judge the digitalised development environment of the museum industry in China, to think about and explore its development and optimization countermeasures. 
Table 1. SWOT-PEST model

\begin{tabular}{lcccc}
\hline SWOT-PEST & POLITICAL & ECONOMIC & SOCIAL & TECHNOLOGICAL \\
\hline STRENGTHS & SP & SE & SS & ST \\
WEAKNESS & WP & WE & WS & WT \\
OPPORTUNITIES & OP & OE & OS & OT \\
THREATS & TP & TE & TS & TT \\
\hline
\end{tabular}

\subsection{SWOT-PEST Analysis on Digitalization of Museum Industry in China}

\subsubsection{Strengths}

(1) State-owned museums dominating achieve a good balance between culture and technology.

According to data, the proportion of state-owned museums in China will reach nearly $70 \%$ in 2020 (Economy pioneer, 2021). The museum market in China with state-owned museums as the mainstay can also better balance the relationship between culture and technology when facing the new situation of integration with technology. Because it actively reacts to the policy and insists on non-profit character, so that avoids catching the blind trend. At present, the most common digital means in the museum is that the interactive games and virtual reality displays are applied around the key collections, which can highlight the cultural value of the collections for comprehensively deepening and understanding. The correct relationship with high-tech information technology as the means and cultural resources as the core, which can keep its mission, promoting culture.

\section{(2) Establishing a special fund}

The document pointed out: "Focusing on the major technological needs for public cultural service system, giving play to the mutual promotion for culture and technology, combining the management reform requirements, incorporating technological innovation into the special plan, In-depth implementation for the science and technology innovation project (Shen, 2015). It means that special funds for the digital and smart museums will provide sufficient maintenance.

(3) Media platforms enhances public attention

In recent years, various museums have opened official Weibo, official accounts in WeChat and short video tik talk to continuously expand the exposure in the market, increasing visibility and popularity among the public, and enhance audiences through interactive communication methods, to accelerate the digital development in the museum industry.

(4) The museum and the company jointly research and develop technology applications

In 2015, the first "National Top Ten Cultural and Museum Technology Products" awards have been held for 7 sessions so far. It is continuously promoted the joint efforts for cultural institutions, scientific research institutes and enterprises, developed a series of new products and technologies, and gradually put them into practical use in the museum, promoting the innovation of technological products in the museum industry.

\subsubsection{Weakness}

(1) Database lacks copyright protection

The digitised museum is based on the development of information technology as the core, and the database is the basis for it. In the construction process, many forms of information in the museum will change, which are mainly displayed and stored in digital. This involves copyright issues, if the necessary copyright protection is lacking, which will affect the development of the museum profound and lasting.

(2) Maintenance and operation cost over-high

Due to the long project time and higher technological, the digitalised museum industry often requires more funds to support. Seen from the current situation, the main adding expenses are technological fields, such as database management fees, cloud computing technology platform rents, and the construction of Internet of Things infrastructure costs, which increased sharply compared with traditional museums in the past.

(3) The museum industry has a small share in the leisure culture market

There is a harmonious and friendly cultural environment in China, hence the museum industry also has a potential development $(\mathrm{Li}, 2018)$. However, comparing the museum industry horizontally with other leisure and 
cultural fields (art performance industry, film industry, etc.), its competitiveness is relatively weak, and its market share is small.

(4) Network Infrastructure is not yet mature

Whether the network infrastructure is perfect or not determines the application quality for various smart devices and digital technologies. Some museums have imperfect network foundations and irregular network connections, resulting in poor coordination between equipment and ports. Meanwhile, the immature network technology has also led to insufficient user groups, which has restricted the digitalised construction process in the museum industry.

\subsubsection{Opportunities}

(1) The active policies accelerate the development of digitalization in the museum industry

Related favourable policies frequently issued at the national level also provide a good external environment for the museum, which has become the main reason for the rapid development of the digitalised museum industry in China. The national level has shown unprecedented attention to the museum industry, and put forward clear instructions to support the digitalised development in the museum industry with innovation system and technological innovation, supported by organizational innovation, and guaranteed by institutional innovation.

(2) The rapid economy has promoted digitalization of the museum industry

At present, the economy has shifted to a stage of high-quality development in China, and industrial structure and consumer demand are rapidly changing to the direction of cultural industries. With the rapid development of industrialization and marketization, the overall economic benefits are also increasing year by year. The museum is contained in the culture industry also shows great potential for sustainable development, ushering in a golden period for development.

(3) The netizens habits changed provides a huge user base for digitalization of the museum industry

It can be seen from the current digitalization of the museum industry that its audience-oriented service work relies on networks and smartphones to provide convenient services with the daily lifestyle most familiar to the public. According to data released by the China Internet Network Information Center (CNNIC), the number of mobile Internet users reached 897 million, accounting for $99.3 \%$ of the total. This means that the Internet usage rate in China is relatively high, and it is mainly mobile phones. Therefore, the change of public Internet habits also provides user support for the digitalised transformation.

\section{(4) The rapid development of high-tech provides technical support}

According to the "Digital Development Report in China", the ability to innovate technology improved constantly, with global top competitiveness in the Internet of Things, cloud computing, intelligent speech recognition and database fields. With the rapid development of related technologies, the Museum has applied these technologies to modern facilities accelerating the pace.

\subsubsection{Threat}

(1) The diversified work no unified standard

At present, the digitalised museum industry in China is still in the exploration stage, and different museums use a variety of technology. With the development of technology, more emerging technologies will be applied to museums in the future. However, the museums are still closed and separated, forming an isolated system , and lack of communication. There is still no sound system and unified standard to promote development in the digitalised museum industry.

(2) Ticket free increasing financial pressure

The "Notice Concerning the Free Opening Museums and Memorials" proposed measures that all museums under the centralized management should be opened to the public free. In other words, the revenue in the museum is restricted (Wang, 2010). However, the operation cost for digitalised museums is more expensive than traditional museums, and the policy measure has reduced the important source income, which undoubtedly puts pressure on the operation of museums.

(3) The Large gap in related professionals

With the rapid development of the Internet, mobile Internet, new media and other technologies, the management and operation of museums will become more digital, intelligent, and scientific. In particular, a large number of high-end compound talents who understand both museum business and information technology are required to 
have participated.

(4) Data systems are complicated and diverse

Digital museum is a new form of museum constituted with information technology as the core and data as the foundation. In other words, data is the most important resource in its museum system. Museum data transmission using the Internet of Things and cloud computing has the function of real-time updates. However, most of the data acquisition from audiences, collections, etc. is indirect and fragmented, which adds to the difficulty for data research and analysis.

\begin{tabular}{|c|c|c|c|c|}
\hline & Political & Economic & Social & Technological \\
\hline Strengths & $\begin{array}{l}\text { State-owned } \\
\text { dominating achieve the good } \\
\text { balance between culture and } \\
\text { technology }\end{array}$ & $\begin{array}{l}\text { Establishing } \\
\text { special fund }\end{array}$ & $\begin{array}{lr}\text { Media } & \text { platforms } \\
\text { enhance } & \text { public } \\
\text { attention } & \end{array}$ & $\begin{array}{l}\text { The museum and the } \\
\text { company jointly } \\
\text { research and develop } \\
\text { technology applications } \\
\text { in the museum }\end{array}$ \\
\hline Weakness & $\begin{array}{lll}\begin{array}{l}\text { Database } \\
\text { protection }\end{array} & \text { lacks } & \text { copyright } \\
\end{array}$ & $\begin{array}{ll}\text { Maintenance } & \text { and } \\
\text { operation } & \text { cost } \\
\text { over-high } & \end{array}$ & $\begin{array}{l}\text { The museum } \\
\text { industry has a small } \\
\text { share in the leisure } \\
\text { culture market }\end{array}$ & $\begin{array}{l}\text { Network Infrastructure } \\
\text { is not yet mature }\end{array}$ \\
\hline Opportunities & $\begin{array}{l}\text { The active policies accelerate } \\
\text { the development of } \\
\text { digitalization in the museum } \\
\text { industry }\end{array}$ & $\begin{array}{l}\text { The rapid } \\
\text { economy has } \\
\text { promoted the } \\
\text { development of } \\
\text { the museum } \\
\text { industry }\end{array}$ & $\begin{array}{l}\text { The netizens habits } \\
\text { changed provides a } \\
\text { huge user base for } \\
\text { digitalization of the } \\
\text { museum industry }\end{array}$ & $\begin{array}{l}\text { The rapid development } \\
\text { of high-tech provides } \\
\text { technical support }\end{array}$ \\
\hline Threats & $\begin{array}{l}\text { The diversified work no } \\
\text { unified standard }\end{array}$ & $\begin{array}{l}\text { Ticket free } \\
\text { increases } \\
\text { financial pressure }\end{array}$ & $\begin{array}{l}\text { The large gap in } \\
\text { related professionals }\end{array}$ & $\begin{array}{lr}\text { Data systems } & \text { are } \\
\text { complicated } & \text { and } \\
\text { diverse } & \end{array}$ \\
\hline
\end{tabular}

The swot-pest matrix analysis chart on digitalization of the museum industry in China

\section{Suggestions for Digitalization of the Museum Industry in China}

\subsection{The Technical Guarantee in the Museum}

The digital development of the museum industry is fundamentally different from the past, which depends on science and technology. Seen from the current technical development, the research achievement is far ahead of the actual application. The development of high-new technology, as well as the cooperation between the museum side and technology companies, have helped provide technological breakthroughs for the museum in many ways. However, in terms of practical applications, some projects were suspended after operation for a short period, or were not put into long-term use. There are three roots of reasons, firstly, the excessively high operating costs make the museum hard bearing. Second, there is a lack of sufficient relevant technical professionals for the daily operation. Third, the most of museums transform from traditional museums to "digital museums" and "smart museums", which is no corresponding infrastructure in the initial stage, so that there are limitations in digitalised development. Therefore, it is necessary to "prescribe the right medicine" and take corresponding measures. First of all, museums should not only rely on government financial appropriations, but should strengthen their competitiveness, open up channels, and raise funds for their own development. Secondly, strengthen the professional ability of museum staff, provide them with opportunities for further study, and at the same time use high-end talents in recruitment. In addition, it is necessary to speed up the renovation of the old buildings in museums, and keep up with the development needs as soon as possible.

\subsection{Adjustment of the Organizational Structure in the Museum}

Another characteristic of digitalization in the museum industry is the efficient dissemination of information and 
data, as well as the redevelopment and utilization of data. This is completely different from traditional museums in the operating characteristics and works business. Therefore, digitalization of the museum industry requires corresponding changes in the new work pattern, workflow, and organizational structure. First of all, traditional museums are mainly divided into important tasks around their duties of collection, protection, display, and education. However, the integration of new technologies has changed the original focus. Traditional museums spend a lot of manpower on the collection of related information and protection, while the digitalised museum with the intervention of technology reduces a lot of tedious work. While the museum is developing towards digital and smart, the focus of it has shifted to "data". For example, how to use collected data for reuse, or how to use audience data to improve the quality. Therefore, it is necessary to reshape a new work pattern centred on "data". Secondly, the work process should be changed accordingly with the work pattern adjusted. The workflow of a traditional museum is collecting, login, display, and education, while the workflow of digitised museums has become the technological collecting, digital display. Therefore, the business process has changed from a process centred on physical objects to a process such as collection data, spatial data, and audience data. Finally, it is organization restructuring. The basic organizational structure of a traditional museum is composed of three parts: the management department, the preservation and exhibition department, and the collection protection. However, the integration of technology makes the previous organizational structure no longer suitable for new needs. The new work focuses on "data", so data has become the core of the museum, and its organizational structure should be developed in accordance with the new business.

\subsection{Establishment of Museum Standards}

The uneven development in digitalised museums industry at this stage is mainly due to the use of different technologies and the differences in individual conditions. The development of differentiation makes it difficult to have an overall long-term development. Therefore, it is necessary to establish a unified standard system. The content of the standard mainly revolves around equipment infrastructure standards, data usage, technical standards, and so on. However, the existing system norms are the classification system with certain standards, the corresponding score for museums depending on the number of main collections, staff support, and hardware facilities. The relevant standards for digitalization only make requirements for video screening, computer touch screens and other facilities. Obviously, it is not enough to standardize the development of digitalization. Therefore, it is necessary to strengthen the relevant core business content such as technical standards and data used in the existing standards and regulations.

\section{Conclusion}

The digitalised development of the museum industry has become the main trend in China. Although it has only begun to explore for 30 years, it has reached the same level as advanced level in the world, and even leading in some respects. The academic research on digitalization of the museum industry is increasing year by year, and is always actively explored. This is a long road that requires groping between technology, theory, and practice, to find countermeasures and potential difficulties from the existing environment, seize the core elements of the museum in the new era, and make the best use of "data", through the guarantee of technical support, the reshaping of the organizational structure, and the improvement of unified standards and specifications, promote the digitalised development of museum industry in China.

\section{References}

Chen, G. (2013). Smart Museum——The New Trend of Digital Museum Development. Chinese Museum, (4), 4-11.

Chen, Y. (2016). SWOT analysis method and its application in enterprise strategic management. Enterprise Reform and Management, (21), 18-19.

China Internet Network Information Center. (2021). Retrieved 3 January 2022, from <http://www.cnnic.net.cn/hlwfzyj/hlwxzbg/hlwtjbg/202102/P020210203334633480104.pdf

Economy pioneer. (2021). Retrieved $3 \quad$ January 2022, from https://baijiahao.baidu.com/s?id=1700623369394308999\&wfr=spider\&for=pc

Li, L. M. (2018). Research on the Evaluation, Structure and Efficiency of China's Leisure Industry Development. East China Normal University.

Li, Y. Q. (2016). Analysis on the Education of Poor Students in Higher Vocational Colleges---Based on Maslow's Hierarchy of Needs Theory and the Perspective of SWOT-PEST Analysis. Culture and Education Data, (22), 131-132. 
$\begin{array}{lllllll}\text { Shen, } & \text { J. } & \text { (2015). } & \text { Retrieved } & 3 & \text { January } & 2022,\end{array}$ http://www.npc.gov.cn/zgrdw/npc/lfzt/rlyw/2016-04/25/content_1987687.htm

The National people's congress of China. (2021). Retrieved 3 January 2022, from http://www.gov.cn/xinwen/2021-07/03/content_5622668.htm

Tong, P. J. (1998). Summary of "Digital Earth". Journal of Geo-Information Science, (Z1), 67-70.

Wang, X.-L. (2010). Opportunities and Challenges Facing the Museum after Free Opening. Qianling Cultural Research, (1), 6.

Zhang, Y. (2016). History and current situation of the Library of Congress in the United States. Journal of Henan Institute of Science and Technology.

Zhao, Y. N. (1997). "Digitalization Determines Our Survival"---A Dialogue between Professor Nigro Ponti and Zhang Shuxin. Wangwang, (18), 3.

\section{Copyrights}

Copyright for this article is retained by the author(s), with first publication rights granted to the journal.

This is an open-access article distributed under the terms and conditions of the Creative Commons Attribution license (http://creativecommons.org/licenses/by/4.0/). 